


\section{Jenaer Historische Arbeiten}

Herausgegeben von

ALEXANDER CARTELLIERI UND WALTHER JUDEICH

Heft 2:

Die Entwicklung der Landeshoheit der Vorfahren des Fürstenhauses Reuß (1122-1329)

Von

DR. WALTER FINKENWIRTH

A. Marcus und E. Webers Verlag in Bonn 1912 


\title{
Die Entwicklung \\ der Landeshoheit der Vorfahren des Fürstenhauses Reuß (1122-1329)
}

\author{
Von \\ DR. WALTER FINKENWIRTH
}

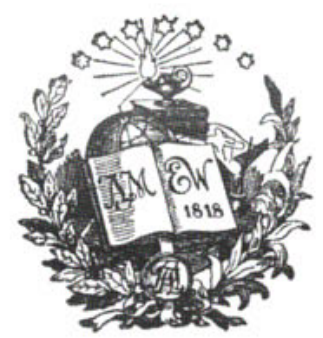

A. Marcus und E. Webers Verlag in Bonn 1912 
ALLE RECHTE VORBEHALTEN 
Meinen beiden Brüdern 



\section{Inhaltsübersicht.}

Einleitung.

Kapitel I: Die ersten Herren von Weida im Vogtland . . . . . . . . . . . . . 12-20

Kapitel II: Die Reichsvogtei der Weidaer die Grundlage ihrer Landeshoheit. . . . . . . 20-35

1. Ursprung und Wesen der Vogtei . . . . . 20-25

2. Landerwerb durch die Vogtei . . . . . . . 25-31

3. Landesherrlichkeit . . . . . . . . . . . 32-35

Kapitel III: Kampf um die Reichsunmittelbarkeit . 35-45

1. Das alte Landgrafengeschlecht von Thüringen $35-39$

2. Die Markgrafen von Meißen . . . . . . 39-45

Kapitel IV: Standesrechtliche Stellung der Herren von Weida und ihrer Nachkommen bis zum Jahre 1329 ... . . . . . . . . . 45-57

1. Die Herren von Weida ein vornehmes Ministerialengeschlecht . . . . . . . . 4 $45-51$

2. Emporsteigen der Vögte zum Herrenstand . 51- 57

Kapitel V: AbschluB der Landeshoheit. . . . . . 57-65

1. Regalien. Straffere Zusammenfassung nach unten . . . . . . . . . . . . 57-61

2. Heinrich II. Reuß, Vogt von Plauen . . . 61-65

Zusammenfassung . . . . . . . . . . . 65-67

Anhang ............... 68-69

Auch an dieser Stelle möchte ich nicht verfehlen, Herrn Prof. Dr. A. Cartellier i für die freundliche Hilfe, die er mir bei der Anfertigung vorliegender Arbeit hat zuteil werden lassen, herzlichst zu danken. Desgleichen spreche ich Herrn Archivrat Dr. B. Schmidt in Schleiz meinen aufrichtigsten Dank aus. Er gab mir die Anregung zu dieser Abhandlung und war zu jeder Auskunft gern bereit. - Kap. I u. II erscheinen gleichzeitig als Jenaer Dissertation. 